Jurnal Keperawatan Silampari

Volume 3, Nomor 2, Juni 2020

e-ISSN: 2581-1975

p-ISSN: 2597-7482

DOI: https://doi.org/10.31539/jks.v3i2.975

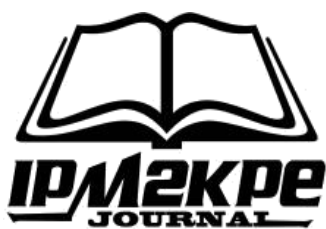

\title{
HASIL BELAJAR PADA MATA KULIAH ASUHAN KEBIDANAN KEHAMILAN DIPENGARUHI PRAKTIK DI LABORATORIUM KEBIDANAN
}

\author{
Theresia Anita \\ Universitas Katolik Musi Charitas \\ theresia.anita@ukmc.ac.id
}

\begin{abstract}
ABSTRAK
Tujuan penelitian adalah untuk mengetahui hubungan pembelajaran praktik di laboratorium kebidanan dengan hasil belajar pada Mata Kuliah Asuhan Kebidanan Kehamilan mahasiswa tingkat II program studi D-3 Kebidanan. Metode penelitian ini menggunakan deskritif analitik dengan pendekatan cross sectional. Hasil penelitian menunjukkan bahwa tingkat pembelajaran praktik di laboratorium adalah kategori tinggi sebesar 59.1\%. dan hasil belajar kategori cukup $72.6 \%$. Hasil uji statistik menunjukkan bahwa $P$-value $=0.029$. Simpulan, adanya hubungan antara pembelajaran praktik di laboratorium kebidanan dengan hasil belajar pada Mata Kuliah Asuhan Kebidanan Kehamilan.
\end{abstract}

Kata Kunci: Asuhan Kebidanan Kehamilan, Praktik Laboratorium

\section{ABSTRACT}

The purpose of this study was to determine the relationship between practical learning in the midwifery laboratory and the learning outcomes in the Pregnancy Midwifery Care Subjects of the Level II D-3 Midwifery students. This research method uses descriptive-analytic with the cross-sectional approach. The results showed that the level of practical learning in the laboratory was a high category of 59.1\%. And category learning outcomes are $72.6 \%$. Statistical test results show that the P-value $=0.029$. There is a relationship between practical learning in midwifery laboratories and learning outcomes in the Pregnancy Midwifery Care Course.

Keywords: Pregnancy Midwifery Care, Laboratory Practices

\section{PENDAHULUAN}

Mampu melaksanakan asuhan kehamilan merupakan ketrampilan khusus dan kompetensi utama seorang bidan, namun kenyataannya masih banyak lulusan mahasiswa jurusan kebidanan yang belum trampil dalam memberikan asuhan kehamilan, meskipun sudah menempuh mata kuliah asuhan kehamilan (Asiyah, 2019).

Profesi bidan dituntut memiliki kompetensi yang baik karena berdampak pada kualitas pelayanan. Kajian terhadap institusi DIII kebidanan bahwa kompetensi lulusan bidan yang sesuai kebutuhan kerja sekitar $15 \%$. Untuk meningkatkan kompetensi kebidanan diperlukan proses pembelajaran laboratorium yang baik selama pendidikan. (Ardiyanti et al., 2016). Fenomena rendahnya kinerja lulusan Diploma III kebidanan menurut pengguna lulusan, salah satunya disebabkan oleh rendahnya kompetensi 
lulusan. Rendahnya kinerja lulusan berdampak terhadap penilaian kualitas lulusan dan instansi pendidikan Kebidanan (Yosi, 2016).

Hasil penelitian yang dilakukan Sudarmi pada tahun 2016 menunjukkan bahwa mutu pembelajaran praktik laboratorium di prodi DIII kebidanan tanjungkarang belum sesuai dengan standar, sebagian besar mahasiswa kurang puas mendapatkan pelayanan pembelajaran praktik laboratorium kebidanan yang diberikan oleh dosen dan petugas laboratorium. Diperlukan langkah-langkah untuk meningkatkan mutu pembelajaran praktik laboratorium kebidanan dengan menerapkan konsep PDCA (Plan-Do-ChekAct), dan untuk pengembangan dimensi mutu pembelajaran praktik laboratorium, dalam kualitas pelayanan yaitu dengan peningkatan: kehandalan (reliability), daya tanggap (respon-siveness), kepastian (assurance), empati (emphaty) dan berwujud (tangible) (Sudarmi, 2016).

Institusi Pendidikan Kebidanan di Indonesia wajib untuk melakukan penjaminan mutu pendidikan, diantaranya dengan menjaga kualitas lulusan. (Yosi, 2016). Penerapan kurikulum pendidikan Diploma III tercakuplah pembelajaran praktikum dan klinis sebanyak $60 \%$ dan pembelajaran teori sebanyak $40 \%$. Pelaksanaan kurikulum melalui dua pendekatan penting, yaitu penguatan pembelajaran di kelas untuk pengembangan materi, dan penguatan pembelajaran di klinik untuk pengembangan keterampilan dan keahlian. Melalui proses pembelajaran praktik peserta didik dituntut untuk mampu menggunakan kemampuan berpikir kritis dalam menganalisis dan menghadapi setiap persoalan, issue dan harapan serta kenyataan dalam kebidanan, sehingga melalui pembelajaran praktik peserta didik dapat mengetahui fenomena yang ada dilapangan (AIPKIND, 2018).

Pembelajaran praktik kebidanan merupakan suatu proses untuk meningkatkan keterampilan kebidanan bagi peserta didik dengan menggunakan berbagai metode pengajaran yang sesuai dengan keterampilan yang diberikan/diajarkan dalam Mata Kuliah Asuhan Kebidanan Kehamilan dan menggunakan peralatan/instrumen kebidanan yang menunjang peserta didik dalam mempraktikkan keterampilannya. Pembelajaran praktik di laboratorium kebidanan juga menjadi bagian dalam proses pendidikan kebidanan yang berfungsi membimbing peserta didik secara sistematis dan terarah untuk dapat melakukan suatu keterampilan. Pembelajaran praktik merupakan proses belajar siswa yang lebih mengutamakan ketrampilan ( $s k i l l)$ yaitu penerapan teori dalam bentuk praktik yang sesungguhnya (AIPKIND, 2018).

Perkuliahan dilakukan secara teori maupun praktik, baik praktik di laboratorium maupun praktik lapangan (klinik). Praktik laboratorium adalah strategi pembelajaran atau bentuk pembelajaran yang digunakan untuk membelajarkan secara bersama-sama kemampuan psikomotorik (ketrampilan), pengertian (pengetahuan), dan afektif (sikap) yang menggunakan saranalaboratorium. Kompetensi pada Mata Kuliah Asuhan Kehamilan terletak pada domain psikomotorik yang lebih besar dibandingkan dengan bobot domain kognitif maupun akfetif. Kegiatan mengajar lebih besar terletak pada pembelajaran praktik (AIPKIND, 2018).

Upaya peningkatan pembelajaran praktik khususnya praktik di laboratorium kebidanan terus ditingkatkan sesuai dengan keterampilan- keterampilan kebidanan yang diperlukan mahasiswa D-3 kebidanan sebagai bekal sebelum masuk pada pembelajaran klinik kebidanan baik di Rumah Sakit, Klinik maupun di Bidan Praktik Mandiri.

Salah satu penerapan belajar, keterampilan pemeriksaan kehamilan awal dan pemeriksan Leopold, dapat menggunakan phamton di laboratorium, namum akan lebih maksimal bila melibatkan pasien langsung (ibu hamil) sebagai sumber belajar konkret. 
Adanya pasien langsung (ibu hamil) memiliki peranan penting sebagai sarana pembelajaran praktik bagi mahasiswa kebidanan tidak dapat digantikan/ditiru dengan phantom secanggih apapun.

Penelitian sebelumnya hanya tentang praktik secara umum, keterampilan kompetensi, mutu pembelajaran. Namun penelitian ini lebih menekankan pada lingkungan laboratorium, pembimbing laboratorium, sarana praktik laboratorium dan panduan praktik laboratorium pada keterampilan pemeriksaan awal ibu hamil dan pemeriksaan Leopold. Penelitian ini bertujuan untuk mengetahui hubungan pembelajaran praktik di laboratorium dengan hasil belajar pada mata kuliah asuhan kebidanan kehamilan.

\section{METODE PENELITIAN}

Rancangan penelitian menggunkan deskritif analitik dengan pendekatan Cross Sectional yakni untuk mengetahui hubungan antara pembelajaran praktek di laboratorium kebidanan dengan hasil belajar Mata Kuliah Asuhan Kebidanan Kehamilan. Sampel penelitian berjumlaj 84 orang yang diambil dengan teknik simple random sampling. Analisis data terdiri dari univariabel, analisis bivariat menggunakan uji chi-square.

\section{HASIL PENELITIAN}

Tabel. 1

Distribusi Frekuensi Pembelajaran Praktik di Laboratorium Kebidanan

\begin{tabular}{lcc}
\hline Pembelajaran Praktik & Frekuensi (n) & Persentase (\%) \\
\hline Tinggi & 50 & 59.1 \\
Rendah & 34 & 40.5 \\
\hline Jumlah & 84 & 100 \\
\hline
\end{tabular}

Sumber: Data primer

Berdasarkan tabel diatas dapat diketahui bahwa sebagian besar responden menilai pembelajaran praktik dilaboratorium kebidanan dalam ketegori tinggi sebanyak 50 respoden $(59.1 \%)$.

Tabel. 2

Distribusi Frekuensi Distribusi Frekuensi

Hasil Belajar Mata Kuliah ASKEB I

\begin{tabular}{ccc}
\hline Hasil Belajar ASKEB I & Frekuensi (n) & Persentase (\%) \\
\hline Baik & 22 & 26.2 \\
Cukup & 61 & 72.6 \\
Kurang & 1 & 1.2 \\
\hline Jumlah & 84 & 100 \\
\hline
\end{tabular}

Sumber: Data primer

Berdasarkan tabel di atas dapat diketahui bahwa hampir sebagian besar responden memiliki hasil belajar yang cukup pada Mata Kuliah ASKEB I (Kehamilan) yaitu sebanyak 61 responden $(72.6 \%)$. 
Tabel. 3

Hubungan Pembelajaran Praktik dengan

Hasil Belajar dalam Mata Kuliah ASKEB I

\begin{tabular}{|c|c|c|c|c|c|c|c|c|c|}
\hline \multirow{4}{*}{$\begin{array}{c}\text { Pembelajaran } \\
\text { Praktik }\end{array}$} & $\mathrm{Ha}$ & Bela & $\mathrm{da}$ & $\mathrm{M}$ & \multicolumn{2}{|c|}{ Asuhan } & & & \multirow{3}{*}{$p$-value } \\
\hline & \multicolumn{6}{|c|}{ Kebidanan I (Kehamilan) } & \multicolumn{2}{|c|}{ Total } & \\
\hline & \multicolumn{2}{|c|}{ Baik } & \multicolumn{2}{|c|}{ Cukup } & \multicolumn{2}{|c|}{ Kurang } & & & \\
\hline & $\mathrm{N}$ & $\%$ & $\mathrm{~N}$ & $\%$ & $\mathrm{~N}$ & $\%$ & $\mathrm{~N}$ & $\%$ & \\
\hline Tinggi & 8 & 16.0 & 41 & 82.0 & 1 & 2.0 & 50 & 100 & \multirow{2}{*}{0.029} \\
\hline Rendah & 14 & 41.2 & 20 & 58.8 & 0 & 0 & 34 & 100 & \\
\hline
\end{tabular}

Sumber: Data primer

Hasil analisis hubungan pembelajaran praktik dengan hasil belajar pada Mata Kuliah ASKEB I (Kehamilan) diperoleh bahwa pada kategori pembelajaran praktik tinggi, hasil belajar Mata Kuliah ASKEB I hampir dari setengah mahasiswa meperoleh hasil belajar cukup sebanyak 41 mahasiswa (82.0\%), dan pada kategori pembelajaran praktik rendah, hasil belajar pada Mata Kuliah ASKEB I sebagian kecil mahasiswa memperoleh hasil belajar cukup sebanyak 20 mahasiswa (58.8\%). Hasil uji stastitik diperoleh $p$-value $=0,029$ artinya terdapat hubungan yang bermakna antara pembelajaran praktik di laboratorium kebidanan dengan hasil belajar dalam Mata Kuliah Asuhan Kebidanan Kehamilan.

\section{PEMBAHASAN}

\section{Distribusi Frekuensi Pembelajaran Praktik di Laboratorium Kebidanan}

Berdasarkan hasil penelitian didapatkan bahwa sebagian besar responden menilai pembelajaran praktik dilaboratorium kebidanan dalam ketegori tinggi sebanyak 50 respoden $(59.1 \%)$.

Hasil penelitian ini menunjukkan bahwa tingkat pembelajaran praktik di laboratorium Kebidanan dapat dikategorikan tinggi karena sudah didukung dengan beberapa faktor yakni tersedianya gedung laboratorium untuk melakukan praktik, kelengkapan instrumen kebidanan yang menunjang dalam melatih keterampilan yang ada dalam perasat Asuhan Kebidanan Kehamilan dan ketersediaannya dosen yang membimbing mahasiswa dalam melatih keterampilan sesuai mata kuliah Asuhan .

Berdasarkan hasil penelitian yang dilakukan Haswita dan Agistiana terdapat hubungan positif sarana prasarana laboratorium dengan pencapain kompetensi tindakan pemenuhan oksigenasi. Adanya penyediaan sarana prasarana yang lengkap dapat menunjang jalannya proses pendidikan untuk mencapai tujuan dalam pendidikan itu sendiri, besar kecilnya penyediaan sarana prasarana yang digunakan oleh mahasiswa dapat menentukan hasil kompetensi tindakan pemenuhan oksigenasi (Haswita, 2016).

Hasil penelitian Rohaeni (2019) diperoleh data hasil belajar Kebidanan nifas dan menyusui sebagian besar dalam kategori B (baik) yaitu 49,3 (75 mahasiswa) dengan perolehan nilai UHAP II (post natal care) dalam kategori A (baik sekali) dan kategori B (baik), yaitu sebesar masing-masing 47,9 (70 mahasiswa). Dan dari hasil analisis correlasi menunjukkan bahwa ada hubungan hasil belajar asuhan kebidanan nifas dan menyusui dengan keterampilan praktik post natal care pada mahasiswa semester III program studi DIII Kebidanan STIKes Cirebon.

Selain itu, hasil pembelajaran yang baik akan berpengaruh pada lulusan tenaga bidan dalam memberikan asuhan yang bermutu tinggi dan pelayanan menyeluruh di masyarakat, dapat mengenal dan menangani sedini mungkin penyulit ataupun penyakit 
saat kehamilan, persalinan dan nifas, dalam rangka untuk meningkatkan kehidupan keluarga yang sehat, perencanaan kehamilan dan kesiapan menjadi orang tua (Rohaeni, 2019).

\section{Distribusi Frekuensi Distribusi Frekuensi Hasil Belajar Mata Kuliah Asuhan Kebidanan Kehamilan}

Berdasarkan hasil penelitian tentang hubungan pembelajaran praktik di laboratorium kebidanan dengan hasil belajar pada mata kuliah Asuhan Kebidanan Kehamilan bahwa hampir sebagian besar responden memiliki hasil belajar yang cukup pada mata kuliah Asuhan Kebidanan Kehamilan yaitu sebanyak 61 responden (72.6\%).

Implikasi teoritis dari penelitian ini adalah bahwa dalam proses pembelajaran praktik laboratorium pada mata kuliah asuhan kehamilan didapatkan hasil praktik yang cukup memuaskan. Pembelajaran praktik laboratorium pada mata kuliah asuhan kehamilan bisa dilanjutkan ke arah praktik klinik kebidanan (Ardiyanti et al., 2016).

Hasil penelitian Asiyah (2019) menunjukkan bahwa Kompetensi dalam asuhan kehamilan pada kelompok perlakuan, pencapaian semua sub kompetensi kategori kompeten

atau nilai absolut 76 atau lebih pada kelompok perlakuan diatas 85\%, pada sum kompetensi palpasi 96,6\% kompeten dan pada auscultasi 100\% kompeten, Untuk Nilai total dari 29 mahasiswa 25 mahasiswa kompeten dan 4 mahasiswa belum kompeten.

\section{Hubungan Pembelajaran Praktik di Laboratorium Kebidanan dengan Hasil Belajar pada Mata Kuliah Asuhan Kebidanan Kehamilan}

Hasil penelitian menunjukkan bahwa terdapat hubungan yang bermakna antara pembelajaran praktik di laboratorium kebidanan dengan hasil belajar pada mata kuliah Asuhan Kebidanan Kehamilan pembelajaran praktik dalam kategori tinggi, hasil belajar mahasiswa pada mata kuliah Asuhan Kebidanan Kehamilan hampir sebagian besar memperoleh nilai yang cukup yaitu sebesar $82.0 \%$ dan sebagian kecil mahasiswa memperoleh nilai cukup yaitu sebesar $58.8 \%$.

Berdasarkan penelitian yang dilakukan oleh Ardiyanti pada tahyn 2016 menyatakan bahwa optimalisasi pembelajaran skill mempengaruhi tingkat kompetensi mahasiswa dalam segi keterampilan. Dalam pembelajaran sudah diupayakan secara optimal namun tetap juga mahasiswa kurang terampil dalam perasat pertolongan persalinan atau pada Mata Kuliah ASKEB II (Persalinan) (Ardiyanti et al., 2016).

Pada ujian praktik di perasat kehamilan khususnya pemeriksaan leopold menurut data sebagian besar harus melakukan ujian praktik ulang, memang pemeriksaan leopold tidak mudah, karena secara teoritis mahasiswa mengerti dan paham, namun secara keterampilan diperlukan ketelitian, keuletan dan semangat dalam melatih kemampuan khusus untuk menguasai teknik pemeriksaan leopold yang benar. Oleh karena itu, mahasiswa dalam kriteria penilaian cenderung berada di point penilaian 1 yaitu mahasiswa tidak mampu melakukannya dengan baik. Langkah dikerjakan tidak sesuai dengan ketentuan dan tidak berurutan, penguji perlu mengingatkan hal-hal yang prinsip, penggunaaan waktu tidak efektif dan efesien.

Berdasarkan nilai uji praktikum tersebut menunjukaan nilai rata-rata mahasiswa dalam ujian praktikum dengan metode OSCE dan non OSCE sudah baik dengan nilai rata-rata > 70.00 sebagai batas kelulusan. Nilai rata-rata terendah pada stasi II yaitu pada pemeriksaan leopold sebesar 70,69. Pemeriksaan leopold adalah suatu teknik pemeriksaan ibu hamil dengan menggunakan cara perabaan atau palpasi abdomen untuk 
mengetahui bagian yang ada dalam rahim seperti: letak janin, posisi janin dan sebagai bahan pertimbangan dalam memperkirakan usia kehamilan. Setiap mahasiswa dituntut untuk trampil dalam pemeriksaan fisik ibu hamil khusus nya pada pemeriksaan leopold yang merupakan bagian yang sangat penting dari pemeriksaan kehamilan (Latifah, 2016).

Hasil penelitian yang dilakukan oleh Harningtyas et al., (2019) mahasiswa memiliki soft skills yang kurang baik. Penyebab mahasiswa masih memiliki soft skills yang kurang baik adalah: 1). Adaptasi dengan lingkungan klinik 2). Perbedaan presepsi antara pembimbing institusi dan lahan praktik, 3). Mahasiswa belum menguasai bagaimana mengaplikasikan proses pembelajaran teori dan praktik. Kesimpulan dari penelitian ini adalah mahasiswa harus mampu mengaplikasikan kemampuan mereka untuk membedakan perbedaan antara praktik klinik yang mereka dapat secara teoritis, praktik yang mereka saksikan dan praktik yang mereka lakukan secara mandiri dan dapat menjadi bidan yang bukan hanya bisa hard skill tetapi juga menjadi bidan yang ahli dalam soft skils

Hasil penelitian Asiyah (2019) menggunakan wilcoxon signed ranks test didapatkan hasil nilai $\mathrm{Z}$ hitung $=-4,649$ dengan $p$ value $0,000>a 0,05$. Penelitian membuktikan Metode pembelajaran bedside teaching cukup efektif untuk meningkatkan kompetensi mahasiwa dalam asuhan kehamilan, bedside teaching biasanya diterapkan langsung diklinik, tapi mendisain pembelajaran laboratorium seperti diklinik dan membawa klien ibu hamil di laboratorium kampus masih jarang diterapkan.

Melakukan asuhan kehamilan perlu ada interaksi dan pengalaman nyata dengan ibu hamil misalnya melatih komunikasi, kodisi dan kelenturan panthom juga tidak bisa sama persis dengan ibu hamil misalnya untuk kompetensi palpasi perlu dilatihkan lansung ke pasien yang tidak bisa didapatkan dari pembelajaran laboratorium yang hanya mengunakan panthom (Asiyah, 2019).

Kompetensi pada Mata Kuliah Asuhan Kebidanan Kehamilan terletak pada domain psikomotorik lebih besar dibandingkan dengan bobot domain kognitif maupun akfetifnya. Implementasi kegiatan mengajar lebih besar terletak pada pembelajaran praktik. Hal ini dapat mempengaruhi hasil belajar mahasiswa, karena hasil belajar pada Mata Kuliah Asuhan Kebidanan Kehamilan adalah pengabungan hasil ujian praktik dan hasil ujian teori baik Ujian Tengah Semester (UTS) maupun Ujian Akhir Semester (UAS) maka diperoleh sebagian besar mahasiswa kebidanan memiliki hasil belajar cukup yaitu sebanyak $72.6 \%$.

\section{SIMPULAN}

Terdapat hubungan yang signifikan antara pembelajaran praktik di laboratorium dengan hasil belajar pada Mata Kuliah Asuhan Kebidanan Kehamilan.

\section{SARAN}

Peneliti selanjutnya menganalisi keterampilan mahsiswa kebidanan dengan metode pembelajaran praktikum tertentu dan tingkat kompetensi mahasiswa dalam keterampilan praktik laboratorium kebidanan. 


\section{DAFTAR PUSTAKA}

AIPKIND. (2018). Kurikulum Pendidikan Diploma III Kebidanan

Ardiyanti Hidayah, Samsi Haryanto, S. J. (2016). Implementasi Proses Pembelajaran Praktik Laboratorium Mata Kuliah Asuhan Kebidanan I (Kehamilan) Mahasiswa Semester II Program Studi D-III Kebidanan Sekolah Tinggi Ilmu Kesehatan Husada Jombang. Hospital Majapahit, 8(1), 34-41. https://doi.org/10.15797/concom.2019..23.009

Asiyah, S. (2019). Pencapaian Kompetensi Mahasiswa Prodi D4 Kebidanan pada Mata Kuliah Asuhan Kehamilan dengan Metode Pembelajaran Laboratorium Klinik di Laboratorium Ante Natal Care STIKES Karya Husada Kediri. Jurnal Kebidanan Midwiferia, 4(2), 24. https://doi.org/10.21070/mid.v4i2.1086

Harningtyas, S., Wurianto, A. B., Raharjanto, A. K., \& Fransisca, R. D. (2019). Implementasi Soft Skills dalam Praktik Klinik Kebidanan Program Studi DIII Kebidanan Stikes Maharani Malang. Jurnal Health Care Media, 3(5), 25-34. https://stikeswch-malang.e-journal.id/Health/article/view/108

Haswita, L. A. (2016). Hubungan antara Sarana Prasarana Laboratorium dan Motivasi Belajar. Jurnal Kesehatan Rustida, 39(4), 274-287

Latifah, U. (2016). Perbedaan Hasil Belajar Praktikum Asuhan Kehamilan dengan Metode Osce ( Objective Structured Clinical Examination ) dan Non Osce Differences in Learning Outcomes of Antenatal Care Practice with Osce and Non Osce Methods For Midwifery Students). Jurnal Ilmu Dan Kesehatan, 7(2), 1-5

Rohaeni, E. (2019). Hubungan Hasil Belajar Asuhan Kebidanan Nifas dan Menyusui dengan Keterampilan Praktik Post Natal Care pada Mahasiswa Semester III Kebidanan Stikes Cirebon. Jurnal Ilmiah Indonesia, 1(1), 1-12

Sudarmi, S. (2016). Analisis Mutu Pembelajaran Praktik Laboratorium sebagai Upaya Peningkatan Mutu Praktik Asuhan Kebidanan di Program Studi D.III Kebidanan Tanjungkarang. Jurnal Kebidanan, 108-118

Yosi, S. (2016). Kinerja Lulusan Diploma III Kebidanan Politeknik Kesehatan Kementerian Kesehatan Padang Menurut Pengguna Lulusan. Jurnal Kesehatan Medika Saintika, 7(1), 103-120 